\title{
A CONDIÇÃO JURÍDICA DO IMIGRANTE TRABALHADOR NA REGIÃO DE FRONTEIRA DO PARANÁ LIMÍTROFE AO PARAGUAI E ARGENTINA ${ }^{1}$
}

\author{
THE LEGAL CONDITION OF IMMIGRANTS WORKERS IN THE \\ PARANA STATE BORDER WITH PARAGUAY AND ARGENTINA
}

\section{LA CONDICIÓN LEGAL DEL TRABAJADOR INMIGRANTE EN LA REGIÓN FRONTERIZA DE PARANÁ LIMITROFE A PARAGUAY Y ARGENTINA}

\author{
Letícia HELFENSTEIN ${ }^{2}$ \\ Maristela FERRARI ${ }^{3}$
}

\begin{abstract}
Resumo: Com o ápice da globalização neoliberal, a fronteira passou a ser temática central em debates políticos que visam regular a mobilidade e o exercício de labor. Nesse viés, o presente artigo objetiva analisar os direitos e as condições de trabalho de imigrantes na região de fronteira do Oeste do Paraná, notadamente daqueles oriundos do Paraguai, do Haiti e de vários países dos continentes africano e asiático. Para a elaboração do presente trabalho, realizamos vasta pesquisa teórico-bibliográfica, bem como pesquisa de campo com trabalhadores imigrantes e autoridades de órgãos públicos, tudo sob a ótica do método qualitativo. O trabalho revela que os imigrantes haitianos, africanos e asiáticos presentes na região fronteiriça do Oeste do Paraná, em sua maioria, têm sido incorporados em agroindústrias, em condições precárias de trabalho; já os imigrantes paraguaios, frequentemente são incorporados em diferentes tipos de trabalho sazonais (construções e atividades rurais) sob condições precárias, inclusive de trabalho análogo ao escravo. Revela ainda que, apesar da lei brasileira continuar avançando no que tange à normatização da imigração - prova disso é a nova Lei de Imigração -, a aplicabilidade das leis e garantias ainda é falha, perpetuando assim a violação de direitos coletivos e individuais e dos princípios basilares da isonomia, igualdade, obrigatoriedade e da proteção ao trabalhador.
\end{abstract}

Palavras chave: Fronteira; Imigrante Trabalhador; Direito.

\begin{abstract}
With the peak of neoliberal globalization, the frontier became a central theme in political debates aimed at regulating mobility and the exercise of labor. In this vein, this article aims to analyze the rights and working conditions of immigrants in the border region of Western Paraná, notably those from Paraguay, Haiti and several countries on the African and Asian continents. For the elaboration of this work, we carried out extensive theoretical and bibliographical research, as well as field research with immigrant workers and public authorities, all from the perspective of the qualitative method. The work reveals that the majority of Haitian, African and Asian immigrants present in the border region of Western Paraná, have been incorporated into agro-industries, in precarious working conditions; Paraguayan immigrants, on the other hand, are often incorporated into different types of seasonal work (construction and rural activities) under precarious conditions, including slave-like labor. It also

\footnotetext{
${ }^{1}$ Trabalho elaborado a partir de Pesquisa de Iniciação Científica Voluntária (ICV) desenvolvida no Laboratório de Estudos Fronteira, Território e Ambiente (GEFTA) da UNIOESTE Campus Marechal Cândido Rondon, intitulada "Migrantes trabalhadores na região de fronteira do Oeste do Paraná limítrofe a Argentina e ao Paraguai: uma análise dos direitos e das condições de trabalho em Marechal Cândido Rondon, Medianeira e Cascavel" sob orientação da Professora Dra . Maristela Ferrari.

${ }^{2}$ Bacharela em Direito, pela Universidade Estadual do Oeste do Paraná - UNIOESTE.

${ }^{3}$ Docente da Graduação e Pós Graduação em Geografia do UNIOESTE - Campus Marechal Cândido Rondon PR.
} 
reveals that, despite the fact that Brazilian law continues to advance with regard to the standardization of immigration - proof of this is the new Immigration Law - the applicability of laws and guarantees is still flawed, thus perpetuating the violation of collective and individual rights and principles principles of equality, equality, mandatory and worker protection.

Keywords: Border; Immigrant Worker; Law.

Resumen: Con el pico de la globalización neoliberal, la frontera se convirtió en un tema central en los debates políticos destinados a regular la movilidad y el ejercicio del trabajo. En este sentido, este artículo tiene como objetivo analizar los derechos y las condiciones de trabajo de los inmigrantes en la región fronteriza del oeste de Paraná, en particular los de Paraguay, Haití y varios países de los continentes de África y Asia. Para la preparación de este trabajo, llevamos a cabo una amplia investigación teórica y bibliográfica, así como una investigación de campo con trabajadores inmigrantes y autoridades públicas, todo desde la perspectiva del método cualitativo. El trabajo revela que la mayoría de los inmigrantes haitianos, africanos y asiáticos presentes en la región fronteriza del oeste de Paraná, se han incorporado a las agroindustrias, en condiciones de trabajo precarias; Los inmigrantes paraguayos, por otro lado, a menudo se incorporan a diferentes tipos de trabajo estacional (construcción y actividades rurales) en condiciones precarias, incluida la mano de obra esclava. También revela que, a pesar del hecho de que la ley brasileña continúa avanzando con respecto a la estandarización de la inmigración (prueba de esto es la nueva Ley de Inmigración), la aplicabilidad de las leyes y garantías sigue siendo defectuosa, lo que perpetúa la violación de los derechos y principios colectivos e individuales. Principios de igualdad, igualdad, obligatoria y protección del trabajador.

Palabras llave: frontera; Trabajador inmigrante; Derecho.

\section{Introdução}

Não há como desvincular os fluxos migratórios da história da humanidade. Seja pelas causas de ordem natural, que motivaram principalmente o nômade primitivo, seja pelas de ordem econômica e social, hoje preponderantes, o homem nunca parou de circular pelo globo, levando consigo extensa bagagem política, apta a moldar e remodelar o mundo (CAVARZERE, 1995). Assim sendo, a imigração, em diversos contextos históricos, foi determinante para a formação e construção econômica, cultural e social dos países. Foi ela que originou todas as nacionalidades e forjou a identidade de cada nação ao longo dos tempos (BATISTA, 2009).

$\mathrm{Na}$ atualidade, a imigração internacional tem se apresentado como uma das grandes problemáticas mundiais. Econômicas, sociais, militares, sanitárias, ambientais, políticas, religiosas, dentre outras, as razões que levam as pessoas a deixar seu país de origem são numerosas. Migrante legal ou ilegal, refugiado ou requerente de asilo, essas mobilidades humanas desenham hoje um mundo em movimento (VICTOR, 2015). Frente a tal fenômeno, observa-se que a problemática da imigração internacional e da fronteira está no centro dos debates políticos e midiáticos. Na política, enquanto os direitos humanos deveriam ser o ponto central dos debates, o que se vê são discursos, por vezes, nacionalistas e xenofóbicos, especialmente dentro de determinados países do Hemisfério Norte, onde, nas últimas décadas, uma das respostas aos problemas colocados pelos movimentos migratórios internacionais têm sido a construção de muros fronteiriços e a criminalização dos migrantes (VICTOR, 2015).

Entre 2000 e 2010, o número de migrantes estrangeiros no Brasil quase dobrou, isto é, teve um crescimento de 86,7\%. Em 2000 o Censo Demográfico Brasileiro registrou a entrada de 143.644 mil migrantes estrangeiros, já em 2010, foi registrada a entrada de 286.468 mil migrantes internacionais oriundos de vários países da escala mundial (INSTITUTO 
EM

QUESTÃO

V.13 N. $02 \downarrow 2020$

pág. 114-129

BRASILEIRO DE GEOGRAFIA E ESTATÍSTICA, 2010). Já entre 2010 e 2015 foi registrada, pela Polícia Federal, a entrada de 216.781 imigrantes no país (POLÍCIA FEDERAL, 2017 apud VARELLA, OLIVEIRA, et al., 2017). Em 2016, 123.851 indivíduos solicitaram a expedição do Registro Nacional de Estrangeiros junto à Polícia Federal e, em 2017, esse número decaiu para 103.067 (POLÍCIA FEDERAL, 2016; POLÍCIA FEDERAL, 2017).

No Paraná, a região oeste do estado, desde 2010, vem sendo destino de muitos imigrantes haitianos, africanos e asiáticos. Em sua maioria, os imigrantes vêm sendo empregados como trabalhadores das agroindústrias do Oeste do Paraná. Já os imigrantes paraguaios são normalmente empregados como trabalhadores do campo ou na construção civil. Assim, a região fronteiriça do Oeste do Paraná, tem sido destino de inúmeros imigrantes desde o começo do século XXI. Portanto cabe indagar: sob que condições humanas e de trabalho os imigrantes são contratados? A legislação brasileira do trabalho lhes assegura os mesmos direitos e garantias dos trabalhadores brasileiros? Qual a condição jurídica dos sujeitos que imigram ao Brasil? Essas são questões que guiam o presente trabalho, cujo objetivo central é analisar os direitos e as condições de trabalho dos imigrantes na região de fronteira Oeste do Paraná.

Os principais procedimentos operacionais deste trabalho consistiram em revisão teórico bibliográfica sobre migração, fronteira, diretos trabalhistas, legislação de trabalho nacional e internacional, bem como pesquisa de campo, realizada na região fronteiriça, notadamente nas cidades de Guaíra, Marechal Cândido Rondon, Cascavel e Toledo. O método de pesquisa adotado foi o qualitativo, tendo em vista que esse método respondeu de maneira mais eficiente as indagações do presente trabalho.

\section{Entendendo o conceito de migração}

De acordo com Santos (2005) a palavra migração deriva do latim, e significa "mudar de habitação, passar de um lugar para outro, ir se embora, sair [...]. Já o termo migrante designa grupo de pessoas ou indivíduo que se desloca de um lugar para outro. Na linguagem mais usual migrante significa mão de obra barata e prestador de serviço de baixa qualificação" (SANTOS, 2005, p. 61). A Organização Internacional do Trabalho - OIT (1949, on-line), por sua vez, define o imigrante trabalhador como aquela "pessoa que emigra de um país para outro com vista a ocupar um emprego que não seja por sua conta própria; inclui todas as pessoas admitidas regularmente na qualidade de trabalhador migrante". A Organização Internacional de Migração - OIM (2009, p. 46), de maneira semelhante, conceitua o imigrante econômico/trabalhador como o indivíduo "que deixa o seu lugar de residência habitual para se instalar fora do seu país de origem, a fim de melhorar a sua qualidade de vida".

$\mathrm{Na}$ literatura geográfica, a imigração tem sido largamente analisada sob diversas perspectivas, dentre elas, as diásporas, conflitos políticos e religiosos, as crises econômicas, o desemprego, desigualdades econômicas, dentre outros fatores que levam os indivíduos a migrarem de um país ao outro. Mas, não basta apenas entender o significado das migrações, é preciso também compreender suas causas ou fatores, pois migrar não é apenas sair de uma região ou país em direção a outro, significa também sair de um contexto polític o, econômico e social para inserir-se ou não em outro contexto (POVOA NETO; FERREIRA, 2005). Ao imigrar, o sujeito deixa para trás o território no qual sempre esteve inserido, e com ele todas as suas perspectivas econômicas, políticas e culturais. Ultrapassada essa "desterritorialização", advém a "reterritorialização", isto é, a nova inserção do indivíduo no 
ambiente em que passou a viver, sentindo e experimentando todas as novas perspectivas do lugar, deixando de lado, ou não, todo o simbolismo de seu local de origem. Daí decorre o caráter multifacetado das migrações, diversas concepções socioculturais, econômicas e políticas em choque diariamente (HAESBAERT, 2005). Portanto, não se trata da simples mobilidade de uma localidade para outra, mas de atravessar fronteiras políticas e de todo um processo de inclusão ou reterritorialização em novo território político cultural, cujos habitantes, por diferentes razões nem sempre são receptivos .

Nesse sentido, Ianni (2014, p. 153) enfatiza que os imigrantes se deslocam

para lugares próximos e distantes, envolvendo mudanças mais ou menos drásticas nas condições de vida e trabalho, em padrões e valores socioculturais. Deslocam-se para sociedades semelhantes ou radicalmente distintas, algumas vezes compreendendo culturas ou mesmo civilizações totalmente diversas [...]. Assim, se diversificam e multiplicam as experiências e as vivências, as surpresas e os horizontes. Tudo o que parecia natural, único, indiscutível ou definitivo logo se revela relativo, discutível, problemático.

Diversos autores, inseridos em distintos contextos, apontam à necessidade de se considerar, antes de tudo, a imigração como um fenômeno social. Nesse sentido, para Zolberg (2006), por exemplo, a imigração internacional envolve não apenas o movimento de um lugar para outro, mas sim a transferência de uma pessoa da jurisdição de um Estado para a de outro e, por conseguinte, a eventualidade de aceitação, da sensação de pertencimento dessa pessoa nessa nova comunidade política. Nesta direção, consoante as reflexões de Haesbaert (2005) e Preuss (2008), Siciliano (2013) infere que a política migratória está sempre relacionada às ideias de cidadania e jurisdição, e, assim sendo, é também um fenômeno jurídico. Logo,

sendo um fenômeno jurídico, são os textos normativos que definem uma política migratória, estabelecendo quem são, e em quais condições, os estrangeiros que serão titulares de direitos, e de quais direitos. As políticas migratórias, portanto, variam significativamente de um Estado para outro, ou ao longo da história de um mesmo Estado, de maneira que políticas de emigração e imigração muitas vezes atingem matrizes complexas de diferentes normas e práticas (SICILIANO, 2013, p. 9-10).

Nessa acepção, no período atual, da globalização neoliberal, uma das questões centrais dos debates políticos sobre fronteira e migração, notadamente em países ditos desenvolvidos, têm sido a aceitação ou não de imigrantes em outros territórios nacionais. Enquanto os direitos humanos deveriam ser o ponto central dos debates, o que se vê são discursos, por vezes, nacionalistas e xenofóbicos, especialmente dentro de alguns países do Hemisfério Norte onde, nas últimas décadas, uma das respostas aos problemas colocados pelos movimentos migratórios internacionais têm sido a construção de muros fronteiriços e a criminalização dos migrantes (VICTOR, 2015). Outra questão importante sobre estudos migratórios diz respeito às condições da travessia das fronteiras políticas entre Estados nacionais. Diferentemente do período das grandes explorações coloniais, atualmente, atravessar uma fronteira político territorial sem a permissão do Estado nacional, implica em criminalizar o imigrante. Em países da Europa e nos Estados Unidos, desde o começo do século XXI, as políticas migratórias parecem crescer no sentido de desumanizar e criminalizar pessoas indocumentadas (por vezes, migrantes forçados) (VICTOR, 2015). Neste sentido, um estudo sobre migrações internacionais não se reduz simplesmente ao conceito e ao fenômeno da migração, mas igualmente da fronteira política entre Estados nacionais. Compreender a 
migração significa ao mesmo tempo, se debruçar sobre as fronteiras políticas impostas dentro do sistema mundial. Hodiernamente, muitos imigrantes de regiões pobres tentam legalmente ou ilegalmente atravessar fronteiras em busca de melhores condições de vida e de trabalho. Neste sentido, parece ser bastante relevante abordar a problemática dos direitos dos imigrantes trabalhadores.

\section{O direito brasileiro e o imigrante}

No país, indubitavelmente a questão migratória recebeu destaque na Constituição Brasileira no momento em que foi concebido o princípio da isonomia: "Art. 50. Todos são iguais perante a lei, sem distinção de qualquer natureza, garantindo-se aos brasileiros e aos estrangeiros residentes no país a inviolabilidade do direito à vida, à liberdade, à igualdade, à segurança e à propriedade [...]" (CONSTITUIÇÃO FEDERAL, 1988), isto é, os estrangeiros que entram no Brasil e passam nele a residir, observados todos os requisitos legais, como por exemplo, o Visto de Permanência, passam a gozar dos mesmos direitos e garantias que os brasileiros, exceto os direitos políticos. Na acepção de Nicoli (2011, p. 51),

[...], presumir a igualdade perante a ordem jurídica e efetivá-la no plano concreto, por meio da garantia de direitos e proteção ao trabalho prestado pelo imigrante, é a única forma de assegurar-lhe uma existência condizente com a sua essencialidade de pessoa humana, que ultrapassa a sua contingente condição de migrante.

Com efeito, denota-se que a ordem democrática estabelecida pela Constituição de 1988 favorece a mobilidade internacional em direção ao Brasil, sendo garantido aos estrangeiros residentes no país, em situação regular ou irregular, como já mencionado, todos os direitos sociais e civis intrínsecos aos nacionais, salvo as ressalvas taxativas feitas pelo próprio texto constitucional (SILVA, 2015). Logo, por exemplo, a pesquisa e a lavra de recursos minerais e o aproveitamento dos potenciais de energia hidráulica não poderão ser efetuados por estrangeiros, mesmo os residentes (Art. 176, $\S 1^{\circ}, \mathrm{CF}$ ). De igual modo, "não podem ser proprietários de empresa jornalística e de radiodifusão sonora e de sons e imagens, nem responsáveis por sua administração e orientação intelectual" (SILVA, 2015, p. 343), conforme o Art. 222 da $\mathrm{CF}$, de modo que a atividade é privativa de brasileiros natos ou naturalizados há mais de dez anos (BRASIL, 1988; SILVA, 2015). Quanto à supressão de direitos políticos, Wermuth e Aguiar (2017, p. 249) ponderam:

Sem a possibilidade de participação política nas decisões que lhes digam respeito, nenhuma mudança no sentido de integração desses sujeitos será efetiva. A efetivação dos direitos fundamentais enquanto processos de lutas, são produtos culturais, são uma reivindicação social, e apenas são possíveis se os imigrantes tiverem o direito de reivindicá-los a todo tempo. Essa limitação do exercício de direitos fundamentais continua colocando os imigrantes em posição inferior em relação aos demais cidadãos brasileiros, sendo-lhes permitido apenas trabalhar e gerar riquezas para o território nacional.

Corroborando esse ponto de vista, Preuss (2008) apud Batista e Parreira (2013, p. 04), expõe que embora exista a promessa de igualdade e dignidade nas constituições contemporâneas, a ausência de uma ligação formal, na prática (como o direito ao voto, a aquisição de nacionalidade, etc.), da pessoa com a sociedade na qual escolheu viver, "pode 
EM

lhe negar qualquer sentido de cidadania e, portanto, capacidade de participar de qualquer forma positivada de democracia no país de acolhida", perpetuando-se assim o sentimento de exclusão, de não pertencimento ao novo território e de inferioridade em relação aos demais cidadãos brasileiros (BATISTA; PARREIRA, 2013).

Nessa linha, infere-se que, malgrado a evolução constitucional no que tange à condição jurídica do estrangeiro no país, primando-se pela igualdade e pela dignidade da pessoa humana, assim como pela solidariedade e liberdade - em que pese a restrição aos direitos políticos -, na prática ainda é necessário estabelecer políticas que insiram efetivamente os imigrantes na vida cidadã brasileira, à exemplo das mencionadas acima. Nesse contexto, a Lei que disciplinava a entrada e saída de estrangeiros no país até 2017 era o Estatuto do Estrangeiro (Lei 6.815/80, alterada pela Lei 6.964/81), a qual foi revogada pela Lei 13.445, de 24 de maio de 2017, que instituiu a nova Lei da Imigração. Aquela tratava o estrangeiro como uma ameaça à segurança nacional e dificultava o processo de regularização migratória, esta, ao revés, expõe o repúdio à xenofobia, ao racismo e a outras formas de discriminação, além de desburocratizar todo o processo imigratório (BRASIL, 1981; BRASIL, 2017).

A nova Lei de Imigração (2017) sobreveio para garantir aos imigrantes, por exemplo, os direitos de reunião para fins pacíficos e de associação sindical e permite o exercício de cargo, emprego ou função pública, com exceção de concursos reservados a brasileiros natos. O Imigrante poderá também se manifestar politicamente, embora a regulamentação do direito ao voto continue a mesma, tendo em vista que a Constituição Federal, hierarquicamente superior, não prevê esse direito aos imigrantes internacionais (BRASIL, 2017).

Nesta senda, a política migratória brasileira passou a ser regida por vários princípios, destacando-se a "universalidade, indivisibilidade e interdependência dos direitos humanos" (Art. $3^{\circ}, \mathrm{I}$ ) e o "repúdio e prevenção à xenofobia, ao racismo e a quaisquer formas de discriminação" (Art. 30, II). Ainda, o Art. 4\%, caput, da Lei cuidou de reproduzir o princípio da isonomia estabelecido no Art. $5^{\circ}$, caput, da Constituição e, além disso, de conferir ao imigrante, expressamente, uma série de direitos outrora negados, dentre eles: direitos e liberdades civis, sociais, culturais e econômicos (Art. $4^{\circ}, \mathrm{I}$ ); reunião familiar do migrante com seu cônjuge ou companheiro e seus filhos, familiares e dependentes (Art. $4^{\circ}$, III); amplo acesso à justiça e à assistência jurídica integral gratuita aos que comprovarem insuficiência de recursos (Art. $\left.4^{\circ}, \mathrm{IX}\right)$; educação pública, vedada a discriminação em razão da nacionalidade e da condição migratória (Art. $4^{\circ}, \mathrm{X}$ ); isenção das taxas de que trata esta Lei, mediante declaração de hipossuficiência econômica (Art. $4^{\circ}$, XII), etc. (BRASIL, 2017).

No que concerne aos direitos sociais, os benefícios e avanços são igualmente iniludíveis. Isto pois, a Lei fixou a inclusão social, laboral e produtiva do migrante por meio de políticas públicas como um princípio norteador da política migratória brasileira (Art. $3^{\circ}$, $\mathrm{X})$, assim como o acesso igualitário e livre do migrante a serviços, programas e benefícios sociais, bens públicos, educação, assistência jurídica integral pública, trabalho, moradia, serviço bancário e seguridade social (Art. $3^{\circ}, \mathrm{XI}$ ). Logo, se constituem como direitos sociais dos imigrantes, além daqueles já previstos no Art. $7^{\circ}$ e demais da Constituição, a transferência de recursos decorrentes de sua renda e economias pessoais a outro país (Art. $4^{\circ}, \mathrm{V}$ ); a reunião para fins pacíficos (Art. $4^{\circ}, \mathrm{VI}$ ); a associação, inclusive sindical, para fins lícitos (Art. $\left.4^{\circ}, \mathrm{VII}\right)$; o acesso a serviços públicos de saúde e de assistência social e à previdência social, nos termos da lei, sem discriminação em razão da nacionalidade e da condição migratória (Art. $4^{\circ}$, VIII) e a garantia de cumprimento de obrigações legais e contratuais trabalhistas e de aplicação das normas de proteção ao trabalhador, sem discriminação em razão da nacionalidade e da condição migratória (Art. $4^{\circ}$, XI) (BRASIL, 2017). 
EM

Ressalta-se, por fim, como benefício suscitado pela ascensão da Lei, a instituição do "diálogo social na formulação, na execução e na avaliação de políticas migratórias e promoção da participação cidadã do migrante" (Art. 30, XIII). Através de tal princípio, o aparato normativo incentiva a inclusão social dos imigrantes. No que tange à inserção no mercado de trabalho, por exemplo, políticas públicas que estavam sendo implementadas foram estimuladas: já há a descentralização da emissão das carteiras de trabalho daqueles imigrantes acolhidos por razões humanitárias, notadamente nos Estados onde o fluxo migratório é maior; o Programa Nacional de Acesso ao Ensino Técnico e Emprego PRONATEC passou a ofertar o curso de Língua Portuguesa e Cultura Brasileira para Estrangeiros, nos níveis básico e intermediário e o Serviço Brasileiro de Apoio às Micro e Pequenas Empresas - SEBRAE, apoiado pelo Comitê Nacional para os Refugiados CONARE e pelo Alto Comissariado das Nações Unidas para os Refugiados - ACNUR, instituiu o projeto "Refugiado Empreendedor", almejando capacitar refugiados e imigrantes em técnicas e temas relativos à abertura de empresas no país (VARELLA, OLIVEIRA, et al., 2017).

Em contrapartida, Wermuth e Aguiar (2017) assinalam as estagnações e retrocessos da Lei. Além da supressão dos direitos políticos - já reconhecidos por Argentina, Bolívia, Colômbia, Equador, México e Peru - mencionam a inexistência da atribuição da questão migratória a um órgão especializado, permanecendo o atendimento dos imigrantes e o encaminhamento de suas documentações sob responsabilidade da Polícia Federal (AGUIAR; WERMUTH, 2018). Além disso, os autores refletem sobre a concessão de vistos. Sob a ótica da Lei $\mathrm{n}^{\circ}$ 6.815/80, o processo para obtenção de vistos era demasiadamente burocrático, chegando até mesmo a estar condicionado ao exercício de atividade certa e à fixação em determinada região do território nacional, em se tratando do visto permanente, e à validade de apenas 90 dias, prorrogáveis por igual prazo, nos demais casos (AGUIAR; WERMUTH, 2018). A partir de agora, os vistos podem ser: de visita, temporário, diplomático, oficial e de cortesia, extinguindo-se, dessa forma, o visto permanente e criando-se "o instituto jurídico da residência para amparar aquele que pretende se estabelecer no país por um período mais prolongado" (VARELLA, OLIVEIRA, et al., 2017, p. 257).

A burocracia foi limitada, porém algumas restrições ainda são infundadas. Nessa acepção, por exemplo, os autores alertam à concessão do visto temporário. Conforme dispõe o Art. $14, \S 5^{\circ}$, esse tipo de visto "[...] poderá ser concedido ao imigrante que venha exercer atividade laboral, com ou sem vínculo empregatício no Brasil, desde que comprove oferta de trabalho formalizada por pessoa jurídica em atividade no País", sendo essa exigência dispensada "se o imigrante comprovar titulação em curso de ensino superior ou equivalente". Ou seja, para se conceder o visto ao imigrante sem formação acadêmica exige-se a comprovação de emprego sem que ele tenha sequer vindo ao país, o que, na prática, é improvável de acontecer, a não ser que as empresas interessadas sejam multinacionais com capacidade internacional de recrutamento, ficando, em verdade, portanto a cargo da empresa solicitar o visto (VARELLA, OLIVEIRA, et al., 2017; WERMUTH e AGUIAR, 2017).

Nesta toada, insurge-se o viés seletivo da Lei, que pugna pelos migrantes "especializados", isto é, aqueles que atendem às qualificações e demandas do mercado de trabalho, sem representar uma ameaça à economia, expondo-se, dessa maneira, os imigrantes "não qualificados", empobrecidos, "a postos altamente explorados no mercado de trabalho informal" (WERMUTH e AGUIAR, 2017, p. 251), o que acaba por corroborar a imigração irregular, a violação dos Direitos Humanos dos imigrantes, as deportações e expulsões e até mesmo o tráfico e contrabando de imigrantes (WERMUTH; AGUIAR, 2017). 
EM

QUESTÃO

V.13 N. $02 \downarrow 2020$

pág. 114-129

\section{$O$ imigrante frente ao direito trabalhista brasileiro}

Para regulamentar o labor de nacionais e estrangeiros no Brasil, a legislação pátria, além de contar com os Direitos Sociais Relativos ao Trabalhador (Arts. $7^{\circ}, 8^{\circ}$ e $9^{\circ}$ da CF) e com a CLT, conforme supracitado, baseia-se nas Convenções da Organização Internacional do Trabalho (OIT). Tais convenções são tratados internacionais, sujeitos a ratificação pelos Estados Membros da Organização, que visam orientar políticas e ações públicas para aperfeiçoar as condições e práticas de trabalho em todo o mundo. Algumas foram ratificadas pelo Brasil, como a Convenção $\mathrm{n}^{\circ} 19$, de 1925 , que acrescentou ao acervo normativo pautas relativas à igualdade de tratamento dos trabalhadores estrangeiros e nacionais em matéria de indenização por acidentes no trabalho; e a Convenção ${ }^{\circ}$ 97, de 1939, sobre os direitos dos trabalhadores migrantes (ORGANIZAÇÃO INTERNACIONAL DO TRABALHO, 2017).

Entretanto, das 189 Convenções da OIT, dezessete não foram ratificadas pelo Brasil, como por exemplo, a Convenção $\mathrm{n}^{\circ} 143$, de 1975, acerca das Imigrações Efetuadas em Condições Abusivas e Sobre a Promoção da Igualdade de Oportunidades e de Tratamento dos Trabalhadores Migrantes, com destaque para o Art. $6^{\circ}$, onde é possível encontrarmos sanções administrativas, penais e civis rígidas, para aqueles que usarem o emprego ilegal de trabalhadores migrantes. Outro dispositivo normativo não ratificado pelo Brasil é a Convenção da Organização das Nações Unidas (ONU) para Proteção dos Trabalhadores Migrantes e seus Familiares, que, nas palavras de Batista e Parreira (2013, p. 10) têm como proposta 'diminuir a 'relatividade' da situação do trabalhador migrante no país de destino, onde geralmente lhe são negados direitos sob o argumento de ordem pública, proteção de interesses de nacionais ou segurança nacional". Para esses autores, seria importante observar que:

[...], dentre os países que ratificaram, não se inclui nenhum que seja destino de fluxos migratórios. Este é um dado interessante, especialmente se considerarmos que entre os anos de 1995 e 2000, Europa e EUA receberam, em conjunto, em torno de 12 milhões de imigrantes. Todos os Estados que ratificaram a Convenção são países periféricos, com alto índice de emigrantes (BATISTA; PARREIRA, 2013, p. 10).

Sob a ótica de Cavarzere (1995, p. 130), a Convenção procura abranger os direitos humanos dos imigrantes regulares e irregulares, bem como de seus familiares,

[...], acreditando que a oferta de emprego a trabalhadores migrantes em situação irregular diminuirá, se os direitos humanos fundamentais dos mesmos forem reconhecidos mais amplamente, além do que, a concessão de direitos adicionais aos trabalhadores migrantes em situação regular incentivará todos os imigrantes e empregadores a respeitar e cumprir as leis e os procedimentos estabelecidos nos Estados interessados.

Ao refletirmos sobre tais normativas (dispositivos não ratificados), constatamos que, assim como em outras esferas, muitos direitos, tanto processuais quanto materiais, encontramse distantes, tanto no papel, quanto na prática, daqueles que residem em território brasileiro. Não obstante, dia após dia, muitos direitos trabalhistas concedidos são violados perpetuando a aplicabilidade do Código Penal Brasileiro, sobretudo no que tange aos crimes contra a Organização do Trabalho (Título IV, Artigos 203 a 207, CP) e a Redução à Condição de Trabalho Análogo ao de Escravo (Art. 149, CP) (CÓDIGO PENAL, 1940).

Em âmbito federal, entre 2010 e 2015, o Ministério Público Federal brasileiro instaurou 3.812 procedimentos extrajudiciais para apurar práticas relacionadas ao trabalho 
escravo. Além disso, foram autuadas 880 ações penais e abertos 2.993 inquéritos policiais correspondentes só ao crime previsto no art. 149 do CP. Tais dados, divulgados em janeiro de 2016, constam de levantamento da Câmara Criminal do respectivo órgão. Só entre 2014 e 2015 o Grupo Especial de Fiscalização Móvel (GEFM), em conjunto com membros do Ministério Público Federal, Ministério Público de Trabalho e Ministério do Trabalho e Emprego, resgatou 1.877 pessoas em condições análogas à de escravidão ${ }^{4}$.

\section{A aplicabilidade dos direitos trabalhistas no Paraná}

Em 24 de junho de 2017, a Folha de Londrina (Jornal do Paraná) veiculou matéria intitulada: "Paraná Lidera Ranking de Trabalho Escravo no Sul". A notícia declara que as condições degradantes de trabalho no Sul são tão preocupantes quanto as nas demais regiões do país. O Paraná é o $11^{\circ}$ estado do país com mais trabalhadores resgatados em situação análoga à escravidão. Foram 1.157 desde $2003^{5}$ (FOLHA DE LONDRINHA, 2017). Entre 2010 e 2015, o Ministério Público do Trabalho do Paraná (MPT- PR) recebeu 315 denúncias de trabalho análogo ao de escravo, tráfico de trabalhadores; 168 Termos de Ajustamento de Conduta foram firmados e 25 ações foram ajuizadas na Justiça do Trabalho. Os casos de trabalho análogo ao escravo no Paraná concentram-se na construção civil, madeireiras, reflorestamento, e há tanta incidência no meio urbano como no $\operatorname{rural}^{6}$ (MPTPR, 2015).

Em 13 de maio de 2016, através de notícia intitulada "Operação liberta 20 trabalhadores em condições de escravidão na região de Cascavel (PR)", ", vinculada ao site do Ministério Público Federal (MPF), verificou-se que, naquele ano, apenas um paranaense foi incluído na "Lista Suja do Trabalho ${ }^{8}$ ". Naquela operação, o Grupo Especial de Fiscalização Móvel libertou os 20 trabalhadores mantidos em situação de trabalho análogo ao escravo, na Fazenda Planalto (Guaraniaçu - PR), a cerca de 50 quilômetros de Cascavel. Segundo notícia do Ministério Público Federal, aqueles 20 trabalhadores dormiam em camas de galhos de árvores e colchonetes sujos e rasgados, num alojamento improvisado, feito com pedaços de madeira cobertos com lona plástica preta. As necessidades fisiológicas eram feitas no mato, já que não havia sanitários. A água utilizada para consumo era de um córrego próximo à sede da fazenda (MPF, 2016).

Outra notícia divulgada no site do Ministério Público do Trabalho no Paraná (MPT-

\footnotetext{
${ }^{4}$ Dados disponíveis em: <http://www.mpf.mp.br/pr/sala-de-imprensa/noticias-pr/operacao-liberta-20trabalhadores-em- condicoes-de-escravidao-na-regiao-de-cascavel $>$.

${ }^{5}$ Dados Disponíveis em: <http://www.folhadelondrina.com.br/reportagem/pr-lidera-ranking-detrabalho-escravo-no- sul-980912.html>.

${ }^{6}$ Dados disponíveis em: < http://www.prt9.mpt.mp.br/procuradorias/45-noticias-prt-curitiba/651-mptpr-recebe-mais- de-300-denuncias-de-trabalho-escravo-nos-ultimos-cinco-anos>.

${ }^{7}$ Disponível em: < http://www.mpf.mp.br/pr/sala-de-imprensa/noticias-pr/operacao-liberta-20trabalhadores-em- condicoes-de-escravidao-na-regiao-de-cascavel>.

${ }^{8}$ Lista divulgada e atualizada semestralmente pelo Ministério do Trabalho, com o objetivo de inibir crédito financeiro para empresas Disponíveis em: 〈http://www.folhadelondrina.com.br/reportagem/prlidera-ranking-de-trabalho-escravo-no- sul-980912.html>.

${ }^{8}$ Dados disponíveis em: < http://www.prt9.mpt.mp.br/procuradorias/45-noticias-prt-curitiba/651-mptpr-recebe-mais- de-300-denuncias-de-trabalho-escravo-nos-ultimos-cinco-anos $>$.

${ }^{8}$ Disponível em: < http://www.mpf.mp.br/pr/sala-de-imprensa/noticias-pr/operacao-liberta-20trabalhadores-em- condicoes-de-escravidao-na-regiao-de-cascavel $>$.

${ }^{8}$ Lista divulgada e atualizada semestralmente pelo Ministério do Trabalho, com o objetivo de inibir crédito financeiro para empresas e fazendeiros que utilizarem mão de obra análoga à de escravo.
} 
EM

QUESTÃO

V.13 N. $02 \downarrow 2020$

pág. 114-129

PR $)^{9}$, em 2015, relatou que o GEFM realizou uma força tarefa nos dias 17 e 18 de novembro de 2015, para resgatar oito trabalhadores encontrados em situação análoga à de escravo, no município de São Sebastião da Amoreira (PR), em obras do Governo. O alojamento estava há dias sem água, obrigando os empregados a tomar banho no cemitério municipal. Alimentos não eram fornecidos e os salários estavam atrasados há quase dois meses. Os empregados relataram que sofriam ameaças do proprietário da empreiteira caso denunciassem a situação. O município teve então que assinar um Termo de Ajustamento de Conduta, comprometendose a fiscalizar o cumprimento da legislação trabalhista por parte das empresas que contrata (MPT-PR, 2016).

Em 08 de fevereiro de 2013, treze (13) pessoas foram aliciadas no Paraguai e posteriormente trazidas ao Brasil para laborar sob regime de trabalho análogo ao escravo em reforma de trecho da rodovia 163, no município de Mercedes. Quando deflagrada a situação de trabalho análogo ao escravo, os trabalhadores paraguaios foram intimados/obrigados a deixar o país em três dias sob ameaça de deportação. Conforme reportagem disponibilizada pela ONG Repórter Brasil ${ }^{10}$, a medida, na época, contrariava a Resolução Normativa ${ }^{\circ} 93$ do Conselho Nacional de Imigração, que visa garantir aos migrantes internacionais em situação irregular direitos básicos, bem como o Decreto $n^{\circ}$ 6964, de 29 de setembro de 2009, que promulga o Acordo sobre Residência para Nacionais dos Estados Partes do MERCOSUL. Conforme o artigo $9^{\circ}$ do Acordo, ipsis litteris: “os imigrantes gozarão, no território das Partes, de tratamento não menos favorável do que recebem os nacionais do país de recepção, no que concerne à aplicação da legislação trabalhista [...]". Se constatado que o imigrante foi aliciado e trabalhou em condições análogas à de escravo ele tem o direito de ficar e solicitar sua regularização com isenção de multas e de sanções administrativas.

Atualmente, a nova Lei de Migraçào dispõe que "Art. 30 que a residência poderá ser autorizada, mediante registro, ao imigrante, ao residente fronteiriço ou ao visitante que se enquadre em uma das seguintes hipóteses: [...] tenha sido vítima de tráfico de pessoas, de trabalho escravo ou de violação de direito agravada por sua condição migratória", além disso, conforme o Art. $50, \S 1^{\circ}$ da Lei, a deportação será sempre precedida de notificação pessoal ao deportando, da qual constem, expressamente, as irregularidades verificadas e prazo para a regularização não inferior a 60 (sessenta) dias, podendo o prazo ser prorrogado, por igual período, por despacho fundamentado e mediante compromisso de a pessoa manter atualizada suas informações domiciliares.

Além das ocorrências supracitadas, no mês de março de 2017, o Delegado da Polícia Federal de Guaíra - PR confirmou a ocorrência de mais dois casos de trabalhadores imigrantes submetidos à condição análoga à de escravo, na fronteira com o Paraguai. $\mathrm{O}$ primeiro caso se sucedeu em 2014, em Maracaju dos Gaúchos, zona rural do município de Guaíra, onde sete trabalhadores paraguaios estavam sendo explorados por agricultores locais. Duas pessoas foram detidas. O segundo caso ocorreu em 2015, também na zona rural do município de Guaíra, porém, no distrito de Cruzeirinho, onde 13 (treze) paraguaios encontravam-se em condições trabalhistas degradantes. Uma pessoa foi detida. Ao ser questionado se já havia sido constatada a presença de trabalhadores estrangeiros irregulares, sem a incidência do crime cominado no Art. 149 do Código Penal, o Delegado afirmou que sim. Aos trabalhadores paraguaios, encontrados em situação de trabalho análogo ao escravo,

\footnotetext{
${ }^{9}$ Disponível em: <http://www.prt9.mpt.mp.br/component/content/article?id=784:mpt-pr-resgataoito-trabalhadores- em-situacao-analoga-a-de-escravo-em-obras-de-programa-do-governoestadual>.

${ }^{10}$ Disponível em: < http://reporterbrasil.org.br/2013/03/apos-libertacao-paraguaios-escravizados-saoobrigados-a- deixar-o-pais//> .
} 
EM

QUESTÃO

V.13 N. $02 \downarrow 2020$

pág. 114-129

foram apenas notificados a deixar o país, nenhum amparo legal foi prestado ${ }^{11}$.

No que diz respeito à região de fronteira do Paraná com Paraguai e Argentina, as velhas práticas ainda persistem, como demonstra Ferrari (2010). Para essa autora, a prática do trabalho análogo ao escravo nas regiões de fronteira, do oeste de Santa Catarina, sudoeste e oeste do Paraná, já estava presente desde o final do século XIX. A autora lembra que "em $1^{\circ}$ de maio de 1913, um jornal operário já noticiava a ocorrência de escravidão nos ervais da Companhia Mate Laranjeira, no Oeste do Paraná", e acrescenta que "no processo de exploração e violência sobre os trabalhadores na região fronteiriça do oeste de Santa Catarina, sudoeste e oeste do Paraná, as maiores vítimas foram os índios guaranis do Paraguai" (FERRARI, 210, p.139).

Assim, é possível inferir, conforme igualmente feito por Ferrari (2010), que atualmente as maiores vítimas do trabalho análogo ao escravo na região fronteiriça do Paraná são os nacionais e os paraguaios oriundos da própria região fronteiriça brasileiro-paraguaia, trabalhadores estes vulneráveis e sem quaisquer conhecimentos de seus direitos ou da legislação de trabalho internacional. Nesse sentido, segundo o Procurador Geral do Trabalho de Cascavel, muitos imigrantes em situação irregular, submetidos ao trabalho penoso, deixam de procurar as autoridades por medo de implicações legislativas, como a deportação ${ }^{12}$.

Já com relação aos trabalhadores imigrantes africanos, asiaticos e haitianos presentes hoje na região fronteiriça do Oeste do Paraná, notadamente em Toledo e Marechal Cândido Rondon, tem-se que são empregados em agroindústrias da região sob o mesmo regime de trabalhadores brasileiros. No entanto, vários depoimentos atestam que, embora não sejam submetidos a condições análogas às de trabalho escravo, estes trabalhadores imigrantes são invisíveis às sociedades locais e que cabe aos próprios migrantes receber os recém-chegados. Localmente não há nenhuma organização religiosa ou empresarial que faz a acolhida dessas pessoas e não há interação cultural entre os locais e os imigrantes. Enquanto em Toledo denota-se uma tentativa de reterritorialização, o mesmo não é constatado em Marechal Cândido Rondon, cidade considerada fechada aos imigrantes e com poucas opções de crescimento. Tanto em Toledo quanto em Marechal Cândido Rondon, a maioria dos imigrantes, são contratados para trabalharem em frigoríficos, onde, segundo os próprios imigrantes, as condições de trabalho deixam muito a desejar ${ }^{13}$. O que chama atenção é que, diferentemente do passado, grande parte dos imigrantes entrevistados possuem formação superior. Deste modo, percebe-se que os imigrantes do século XXI, não são os mesmos do século XIX e metade do século XX. Os imigrantes de hoje, possuem formação, tem conhecimento político e se posicionam firmemente defendendo seus ideais políticos, religiosos e culturais.

Sobre as condições de trabalho nos frigoríficos, os imigrantes revelam ser um trabalho árduo e desgastante físicamente ${ }^{14}$. Apesar de os trabalhadores imigrantes estarem sob o regime da legislação trabalhista brasileira, os trabalhos mais difíceis dentro dos frigoríficos parecem ser destinados aos imigrantes. Reclamação constante é da longa jornada de trabalho e da baixa remuneração, o que dá a ideia de exploração dos trabalhadores. Além disso, no interior dos frigoríficos faz muito frio, e por essa razão, os resfriados são constantes implicando na busca por tratamentos médico-hospitalares. Destarte, as condições de trabalho

\footnotetext{
${ }^{11}$ Informações extraídas do Relatório Final da Pesquisa de Iniciação Científica Voluntária intitulado "Migrantes trabalhadores na região de fronteira do Oeste do Paraná limítrofe a Argentina e ao Paraguai: uma análise dos direitos e das condições de trabalho em Marechal Cândido Rondon, Toledo e Cascavel", 2017.

${ }^{12}$ Idem.

${ }^{13}$ Idem.

${ }^{14}$ Idem.
} 
dos imigrantes paraguaios, no Oeste do Paraná, são sem sombra de dúvida as mais precárias e degradantes e isso tem sido confirmado por autoridades da Procuradoria Geral do Trabalho e da Delegacia da Polícia Federal. Enquanto os imigrantes haitianos, africanos e asiáticos são, normalmente, empregados sob o regime de trabalho da legislação brasileira, os paraguaios são submetidos à condições degradantes de trabalho e, sem qualquer assistência político-jurídica são conduzidos a retornarem ao seu país de origem, desrespeitando-se assim as garantias legais previstas no ordenamento jurídico nacional.

\section{Considerações finais}

O trabalho aqui apresentado teve por objetivo analisar os direitos e as condições dos imigrantes trabalhadores na região de fronteira do oeste do Paraná, notadamente daqueles oriundos do Paraguai, Haiti e de vários países dos Continentes Africano e Asiático. Assim, podemos, parcialmente, dizer que na região de fronteira do oeste do Paraná, região limítrofe ao Paraguai e Argentina, imigrantes trabalhadores ainda são submetidos a condições de trabalho degradante, notadamente trabalhadores paraguaios. Ainda que a Lei Trabalhista brasileira seja considerada uma das mais benéficas ao trabalhador, a pesquisa revela que existem grandes lacunas no que tange a vida do trabalhador imigrante ou não. Prova disso é a ineficácia dos mecanismos de prevenção e combate ao trabalho análogo ao escravo. Nesta direção, pode-se pensar que, como solução, o país pode buscar auxílio em Convenções e Tratados Internacionais ainda não ratificados, como a Convenção sobre a Proteção dos Direitos de Todos os Trabalhadores Imigrantes e seus Familiares, da Organização das Nações Unidas (ONU), e a Convenção $\mathrm{n}^{\circ}$ 143, de 1975, da Organização Internacional do Trabalho (OIT), acerca das Imigrações Efetuadas em Condições Abusivas e Sobre a Promoção da Igualdade de Oportunidades e de Tratamento dos Trabalhadores Migrantes. Pode, igualmente, atuar ativamente no cenário internacional, propondo e firmando acordos internacionais que versem sobre medidas cooperativas para extirpar problemas envolvendo a temática, como foi feito, por exemplo, com o Plano Nacional para a Erradicação do Trabalho Escravo, em 2002.

Outra medida alternativa seria investir no acesso à informação, levando ao conhecimento de toda a população sobre os direitos e garantias que circundam o universo do trabalhador imigrante. Com o conhecimento sobre o assunto, mais denúncias seriam realizadas e menos imigrantes teriam medo de expor sua situação.

O trabalho revela ainda, que, diferentemente do passado, hoje os fluxos migratórios se desenham do Sul para o Norte e do Sul para o Sul. Como informam Haebaert e PortoGonçalves (2005), é precisamente a direção dos fluxos migratórios que se modificou sendo, portanto, um dado novo. No entanto, se outrora os imigrantes do Norte para o Sul eram bem acolhidos, na atualidade não se constata a mesma receptividade, há múltiplos preconceitos, dentre eles: religiosos, culturais e xenofóbicos. Isso também é constatado nos fluxos do Sul para o Sul, como, por exemplo, de países africanos em direção ao Brasil, exemplo disso é a própria região fronteiriça do Oeste do Paraná, onde, no senso comum, equivocadamente circula a ideia de que, os trabalhadores imigrantes na região estariam tirando vagas de trabalho que deveriam ser destinadas aos nacionais da região.

Assim, depreende-se que para a real efetivação dos princípios que norteiam a imigração no país - como o repúdio e prevenção à xenofobia, a igualdade de oportunidades ao imigrante e seus familiares e a inclusão social, laboral e produtiva do migrante -, política públicas que aproximem os imigrantes dos nacionais e da vida cidadã brasileira devem continuar sendo implementadas em todos os âmbitos da sociedade civil, ainda mais se 
EM

QUESTÃO

V.13 N. $02 \diamond 2020$

pág. 114-129

considerado o grande preconceito que ainda impera na coletividade.

\section{Referências}

AGUIAR, Jeannine Tonetto de; WERMUTH, Maiquel Ângelo Dezordi. A Criminalização dos Imigrantes em Situação Irregular nos Países-Membros da União Europeia: Institucionalização de um Modelo de Direito Penal de autor? In: XII SEMINÁRIO NACIONAL DE DEMANDAS SOCIAIS E POLÍTICAS PÚBLICAS NA SOCIEDADE CONTEMPORÂNEA. Anais. Santa Cruz do Sul: UNISC, 2016. Disponível em: <https://online.unisc.br/acadnet/anais/index.php/snpp/article/viewFile/14627/3062> Acesso em: 20 jan. 2020.

AGUIAR, Jeannine Tonetto de; WERMUTH, Maiquel Ângelo Dezordi. Direitos humanos e políticas migratórias brasileiras: do Estatuto do Estrangeiro à nova Lei de Migrações, rupturas e continuidades. Culturas Jurídicas: v. 5, n. 10, 2018.

BATISTA, Vanessa Oliveira. O Fluxo Mifratório Mundial e o Paradigma Contemporâneo de Segurança Migratória. Versus, v. 3, p. 68-78, 2009. Disponível em: <https://www.academia.edu/11339781/O_FLUXO_MIGRAT\%C3\%93RIO_MUNDIAL_E_ O_PARADIGMA_CONTEMPOR\%C3\%82NEO_DE_SEGURAN\%C3\%87A_MIGRAT\%C 3\%93RIA> Acesso em: 20 jan. 2020.

BATISTA, Vanessa B; PARREIRA, Carolina G. Trabalho. Imigração e o Direito internacional dos Direitos Humanos. 2013. Disponível em:

<http://www.publicadireito.com.br/artigos/?cod=47a3893cc405396a> Acesso em: 03 jan. 2020.

BAUER, Martin W; GASKELL, George. Pesquisa Qualitativa com Texto, Imagem e Som: um manual prático. Petrópolis: Vozes, 2003.

BRASIL. Decreto no 6964, de 29 de setembro de 2009. Lex: Acordo sobre Residência para Nacionais dos Estados Partes do MERCOSUL.

Disponível em: <http://www.planalto.gov.br/ccivil_03/_Ato20072010/2009/Decreto/D6964.htm>. Acesso em 03 jan. 2020.

BRASIL, Decreto-Lei No 2.848, de 7 de dezembro de 1940. Lex: Código Penal. Disponível em: <http://www.planalto.gov.br/ccivil_03/decreto-lei/Del2848compilado.htm>. Acesso em 06 jan. 2020.

BRASIL. Decreto-Lei $N^{o}$ 5.452. de $1^{\circ}$ de maio de 1943. Lex: Consolidação das Leis Trabalhistas - CLT. Disponível em: <http://www.planalto.gov.br/ccivil_03/decretolei/Del5452.htm>. Acesso em 06 jan. 2020.

BRASIL. Constituição (1988). Constituição da República Federativa do Brasil. Disponível em: <http://www.planalto.gov.br/ccivil_03/constituicao/constituicaocompilado.htm>. Acesso em 03 jan. 2020.

BRASIL. Decreto Lei no 13.445, de 24 de maio de 2017. Lei de Migração. Brasília, 2017. 
EM

QUESTÃO

V.13 N. $02 \downarrow 2020$

pág. 114-129

Disponível em: < http://www.planalto.gov.br/ccivil_03/_ato2015-2018/2017/lei/L13445.htm> Acesso em: 20 jan. 2020.

BRASIL. Resolução Normativa No 93 De 21.12.2010. Lex: concessão de visto permanente ou permanência no Brasil de estrangeiro considerado vítima do tráfico de pessoas. Disponível em: < http://reporterbrasil.org.br/documentos/RN93-2010.pdf>. Acesso em 06 jan. 2020.

CAVARZERE, Thelma Thais. Direito Internacional da Pessoa Humana: a circulação internacional de pessoas. Rio de Janeiro: Renovar, 1995.

FERRARI, Maristela. Conflitos e povoamento na fronteira Brasil-Argentina: Dionísio Cerqueira (SC), Barracão (PR) e Bernardo de Irigoyen (Misiones). Florianópolis: Ed. Da UFSC, 2010.

GOMES, Charles P. Os estudos de imigração: sobre algumas implicações políticas do método. In: POVOA NETO, Helion e FERREIRA, Ademir Pacelli (Orgs). Cruzando Fronteiras disciplinares: um programa dos estudos migratórios. Editora Revan LTDA: Rio de Janeiro, 2005.

HAESBAERT, Rogério. Região e Redes Transfronteiriças em Áreas de Migração Brasileira nos Vizinhos do Mercosul. In: STROHAECKER, Tânia Marques (org.) et al. Fronteiras e Espaço Global. Porto Alegre: AGB-Seção Porto Alegre, 1998. p.59-68.

HAESBAERT, Rogério. Migração e desterritorialização. In: POVOA NETO, Helion e FERREIRA, Ademir Pacelli (Orgs.). Cruzando Fronteiras disciplinares: um programa dos estudos migratórios. Editora Revan LTDA: Rio de Janeiro, 2005.

HAESBAERT, Rogério. Territórios Alternativos. Contexto: São Paulo, 2002.

HAESBAERT, Rogério e PORTO-GONÇALVES, Carlos Walter. A nova dês-ordem mundial. São Paulo: Ed. UNESP, 2005.

IANNI, Octavio. A era do globalismo. 12 ed. Rio de Janeiro: Civilização Brasileira, 2014.

MINISTERIO PUBLICO FEDERAL. Operação liberta 20 trabalhadores em condições de escravidão na região de Cascavel (PR). 2015. Disponível em: <http://www.mpf.mp.br/pr/salade- imprensa/noticias-pr/operacao-liberta-20-trabalhadores-em-condicoes-de-escravidao-naregiao- de-cascavel>. Acesso em 06 jan. 2020.

MINISTERIO PUBLICO DO TRABALHO NO PARANÁ. MPT-PR recebe mais de 300 denúncias de trabalho escravo nos últimos cinco anos. 2015. Disponível em: < http://www.prt9.mpt.mp.br/procuradorias/45-noticias-prtcuritiba/651-mpt-pr-recebe-mais-de-300- denuncias-de-trabalho-escravo-nos-ultimos-cincoanos>. Acesso em 06 jan. 2020.

MINISTERIO PUBLICO DO TRABALHO NO PARANÁ. MPT-PR resgata oito trabalhadores em situação análoga à de escravo em obras de programa do Governo Estadual. 2015. Disponível em:<http://www.prt9.mpt.mp.br/component/content/article?id=784:mpt-prresgata-oito-trabalhadores- em-situacao-analoga-a-de-escravo-em-obras-de-programa-dogoverno-estadual>. Acesso em 06 jan. 2020. 
EM

QUESTÃO

V.13 N. $02 \downarrow 2020$

pág. 114-129

NICOLI, Pedro Augusto Gravatá. A Condição Jurídica do Trabalhador Imigrante no Direito Brasileiro. São Paulo: Ltr, 2011.

ORGANIZAÇÃO INTERNACIONAL DO TRABALHO. Convenção $n^{\circ}$ 19: Igualdade de Tratamento (Indenização por Acidente de Trabalho). Disponível em: <http://www.oitbrasil.org.br/node/446>. Acesso em 10 jan. 2020.

ORGANIZAÇÃO INTERNACIONAL DO TRABALHO. Convenção n ${ }^{\circ}$ 97: Trabalhadores Migrantes. 1949. Disponível em: <http://www.oitbrasil.org.br/node/523>. Acesso em 10 jan. 2020.

ORGANIZAÇÃO INTERNACIONAL DO TRABALHO. Convenção $n^{\circ}$ 143: Imigrações Efetuadas em Condições Abusivas e Sobre a Promoção da Igualdade de Oportunidades e de Tratamento dos Trabalhadores Migrantes. Disponível em: <http://www.oit.org.br/content/convention_no>. Acesso em 10 jan. 2020.

ORGANIZAÇÃO INTERNACIONAL PARA AS MIGRAÇÕES - OIM. Glossário para as Migrações. Organização Internacional para as Migrações: Geneva, 2009, 92 p. Disponível em: <http://publications.iom.int/system/files/pdf/iml22.pdf> Acesso em: 20 jan. 2020.

POLÍCIA FEDERAL. Dados Sincre 2016. Disponível em: <http://www.pf.gov.br/servicospf/imigracao/sincre_2016.xlsx/view>. Acesso em: 20 dez. 2019.

POLÍCIA FEDERAL. Dados Sincre 2017. Disponível em: <http://www.pf.gov.br/servicospf/imigracao/sincre_2017.xlsx/view>. Acesso em: 20 dez. 2019.

POVOA NETO, Helion e FERREIRA, Ademir Pacelli (Orgs). Cruzando Fronteiras disciplinares: um programa dos estudos migratórios. Editora Revan LTDA: Rio de Janeiro, 2005.

RAFFESTIN, Claude. Por uma Geografia do Poder. São Paulo: Ática, 1993.

REPÓRTER BRASIL. Após libertação, paraguaios escravizados são obrigados a deixar o país. 2013. Disponível em: < http://reporterbrasil.org.br/2013/03/apos-libertacao-paraguaiosescravizados-sao-obrigados-a-deixar-o-pais//>. Acesso em 06 jan. 2020.

SANTOS, Milton. A Natureza do Espaço: técnica e tempo, razão e emoção. São Paulo, Hucitec, 1999.

SANTOS, Gislene Aparecida dos. Redes e Território: Reflexões sobre a migração. Redes, sociedade e território. DIAS. Leila Cristina. SILVEIRA. Rogério Leandro Lima da (org.), Santa Cruz do Sul: EDUNISC, 2005. P. 51-78.

SICILIANO, André Luiz. A política migratória brasileira: limites e desafios. Dissertação de Mestrado - Universidade de São Paulo, 2013. Disponível em: <http://www.teses.usp.br/teses/disponiveis/101/101131/tde-03022014-173058/pt-br.php> Acesso em: 25 jan. 2020.

SILVA, José Afonso da. Curso de Direito Constitucional Positivo. 38. ed. São Paulo: 
EM

QUESTÃO

V.13 N. $02 \downarrow 2020$

pág. 114-129

Malheiros, 2015.

VARELLA, Marcelo Dias; OLIVEIRA, Clarice; et al. O caráter humanista da Lei de Migrações: avanços da Lei n. 13.445/2017 e os desafios da sua regulamentação. Revista de Direito Internacional, v. 14, n. 2, 2017. Disponível em: < https://www.publicacoesacademicas.uniceub.br/rdi/article/viewFile/4682/pdf > Acesso em: 20 dez. 2019.

VICTOR, Jean-Christophe. Le dessous des cartes: itinéraires géopolitiques. Edition Tallandier/Arte Éditions: Paris, 2012.

\section{Nota biográfica}

Letícia Helfenstein - Bacharela em Direito pela Universidade Estadual do Oeste do Paraná. Pesquisadora no campo do Direito Imigratório. E-mail: leticia_helf@hotmail.com.

Maristela Ferrari - Docente da Graduação e Pós Graduação em Geografia do UNIOESTE Campus Marechal Cândido Rondon - PR. Coordenadora do Grupo de Estudos sobre Fronteira, Território e Ambiente (GEFTA). E-mail: maristela7ferrari@gmail.com.

Artigo recebido em 10-02-2020

Artigo aceito para publicação em 15-03-2020 